\title{
The role of Nox2-derived ROS in the development of cognitive impairment after sepsis
}

\author{
Marina S Hernandes ${ }^{1,6^{*}}$, Joana C D'Avila ${ }^{3 \dagger}$, Silvia C Trevelin ${ }^{4}$, Patricia A Reis ${ }^{3}$, Erika R Kinjo ${ }^{1}$, Lucia R Lopes ${ }^{2}$, \\ Hugo C Castro-Faria-Neto ${ }^{3}$, Fernando Q Cunha ${ }^{4}$, Luiz RG Britto ${ }^{1}$ and Fernando A Bozza ${ }^{5,7^{*}}$
}

\begin{abstract}
Background: Sepsis- associated encephalopathy (SAE) is an early and common feature of severe infections. Oxidative stress is one of the mechanisms associated with the pathophysiology of SAE. The goal of this study was to investigate the involvement of NADPH oxidase in neuroinflammation and in the long-term cognitive impairment of sepsis survivors.
\end{abstract}

Methods: Sepsis was induced in WT and gp9 ${ }^{\text {phox }}$ knockout mice (gp91 ${ }^{\text {phox- }}{ }^{-}$) by cecal ligation and puncture (CLP) to induce fecal peritonitis. We measured oxidative stress, Nox2 and Nox4 gene expression and neuroinflammation in the hippocampus at six hours, twenty-four hours and five days post-sepsis. Mice were also treated with apocynin, a NADPH oxidase inhibitor. Behavioral outcomes were evaluated 15 days after sepsis with the inhibitory avoidance test and the Morris water maze in control and apocynin-treated WT mice.

Results: Acute oxidative damage to the hippocampus was identified by increased 4-HNE expression in parallel with an increase in Nox2 gene expression after sepsis. Pharmacological inhibition of Nox2 with apocynin completely inhibited hippocampal oxidative stress in septic animals. Pharmacologic inhibition or the absence of Nox2 in gp91 ${ }^{\text {phox }-1-}$ mice prevented glial cell activation, one of the central mechanisms associated with SAE. Finally, treatment with apocynin and inhibition of hippocampal oxidative stress in the acute phase of sepsis prevented the development of long-term cognitive impairment.

Conclusions: Our results demonstrate that Nox2 is the main source of reactive oxygen species (ROS) involved in the oxidative damage to the hippocampus in SAE and that Nox2-derived ROS are determining factors for cognitive impairments after sepsis. These findings highlight the importance of Nox2-derived ROS as a central mechanism in the development of neuroinflammation associated with SAE.

Keywords: Systemic inflammation, Brain, NADPH oxidase, Oxidative stress, Encephalopathy

\section{Introduction}

The clinical observation that sepsis and systemic inflammation affect brain function is not novel [1-3]. However, it was only recently demonstrated that acute brain dysfunction is an independent cause of morbidity and mortality in septic patients [4]. The presence of acute brain dysfunction is a determining factor for long-term cognitive impairments among sepsis survivors. Clinical studies

\footnotetext{
* Correspondence: marinash@icb.usp.br; fernando.bozza@ipec.fiocruz.br ${ }^{\dagger}$ Equal contributors

'Department of Physiology and Biophysics, University of São Paulo, São Paulo, Brazil

5 Instituto de Pesquisa Clínica Evandro Chagas, FIOCRUZ, e Instituto D'Or de Pesquisa e Ensino (IDOR), Rio de Janeiro, Brazil

Full list of author information is available at the end of the article
}

have shown that up to $60 \%$ of sepsis survivors exhibit permanent cognitive deficits and memory loss [5].

Sepsis- associated encephalopathy (SAE) and its longterm consequences in cognitive function are still poorly understood. The use of relevant preclinical models has facilitated the elucidation of central mechanisms, such as mitochondrial and vascular dysfunction, neurotransmission disturbance, inflammation and cell death [6-8]. Some studies have addressed the involvement of reactive oxygen species (ROS), reduced antioxidant capacity, and the accumulation of oxidative stress markers in experimental sepsis [9-11] and in patients [12-17]. Mitochondria are major sources of intracellular ROS and recent studies support the importance of mitochondrial ROS 
for immune cell function $[18,19]$. However, the extent to which mitochondria generate ROS in vivo is still controversial [20]. Another main source of ROS in the brain is NADPH oxidase.

NADPH oxidases are a family of enzymes dedicated to the generation of $\mathrm{ROS}(\mathrm{O} 2 \cdot-)$ via reduction of molecular oxygen [21,22]. Members of the NADPH oxidase family include Nox1 through 5 as well as Dual oxidase 1 and 2 (Duox 1 and Duox 2). In the nervous system, the main isoforms are Nox1, Nox2 and Nox4 [23]. These isoforms have been identified in different cell types, including neurons, endothelial and glial cells [24]. Moreover, NADPH oxidase isoforms are activated by various stimuli, including damage-associated and pathogenassociated molecular patterns (DAMPs and PAMPs), inflammatory mediators and neurotoxins. NADPH oxidase dependent production of $\mathrm{O}^{--}$has been identified as a major contributor to brain injury in cerebral ischemia [25-27], excitotoxicity [28], Alzheimer's disease, Parkinson's disease and other neurological diseases [29].

Here we explored the role of NADPH oxidase in different aspects of the pathophysiology of SAE. We investigated the involvement of NADPH oxidase in neuroinflammation and in the long-term cognitive impairment of sepsis survivors. Our approach included pharmacological inhibition of NADPH oxidase activity with apocynin, as well as the use of genetically deficient (knockout) mice for ${\mathrm{gp} 91^{\text {phox }}}^{\text {phe }}$ (gp91 ${ }^{\text {phox-/-}}$ ), the catalytic subunit of Nox2. We identified Nox2 as a necessary step for glial cell activation in SAE and as a major source of oxidative stress and cognitive impairment in sepsis survivors.

\section{Material and methods}

\section{Animals}

Adult male C57BL/6 (wild-type (WT)) (eight to ten week-old, 25 to $30 \mathrm{~g}$ ) were obtained from the Oswaldo Cruz Foundation (FIOCRUZ), and from the Institute of Biomedical Sciences, University of São Paulo breeding units. Gp91 ${ }^{\text {phox-/- }}$ mice were obtained from Jackson Laboratories (Bar Harbor, ME, USA). The animals had free access to food and water and were maintained on a 12:12 hour light-dark cycle. Experiments were performed with age- and weight-matched animals. All procedures were approved by the Institutional Animal Care Committees of the Institute of Biomedical Sciences, University of São Paulo and the FIOCRUZ, Rio de Janeiro, Brazil.

\section{Sepsis model}

Sepsis was induced by cecal ligation and puncture (CLP), a procedure that generates an acute polymicrobial peritonitis as previously described [30]. Mice were anesthetized with an intraperitoneal (ip) injection of ketamine $(100 \mathrm{mg} / \mathrm{kg})$ and xylazine $(10 \mathrm{mg} / \mathrm{kg})$ and a $1 \mathrm{~cm}$ incision was made on the abdomen. The cecum was exposed and ligated below the ileocecal junction. A double puncture was made using a 22-gauge needle, to induce mild sepsis. Sham-operated animals (controls) underwent an identical laparotomy but without CLP. Alternatively, experimental sepsis was induced by an ip injection of the fecal slurry, which induces acute polymicrobial peritonitis and a septic syndrome similar to CLP. Both models show similar inflammatory response profiles in terms of mortality, blood cytokines and neuroinflammation (data not shown). The intraperitoneal injection of the fecal slurry model was chosen for behavioral studies to avoid surgery and the use of anesthetics that might affect pathways involved in cognitive impairment induced by sepsis. All mice received antibiotic therapy by subcutaneous injection of ertapenem or meropenen $(20 \mathrm{mg} / \mathrm{kg}$ ) (Merck Research Laboratory, Whitehouse Station, NJ, USA) beginning six hours after sepsis induction and then every twelve hours up to day four. Animals received $1 \mathrm{ml}$ of sterile saline subcutaneously (sc) as fluid resuscitation after sepsis induction.

\section{Apocynin treatment}

Apocynin has been widely used as a pharmacological tool to inhibit NADPH oxidase activity [31,32]. Its mechanism of action involves blocking the translocation of the cytosolic subunit $\mathrm{p} 47^{\text {phox }}$ to the plasma membrane, thereby inhibiting Nox2 activation [33]. Apocynin treatment has shown anti-inflammatory effects in some models of inflammatory diseases, such as rheumatoid arthritis [34], Parkinson's disease [32], ALS [35] and brain ischemia [36], as well as in our models of sepsis (data not shown). To access the involvement of Nox2derived ROS in glial cell activation in the hippocampus, WT mice were injected with $20 \mathrm{mg} / \mathrm{kg}$ of apocynin (Sigma-Aldrich, St. Louis, MO, USA) sc 30 minutes prior to the induction of sepsis. Tissue samples were collected at six hours, twenty-four hours and five days post-sepsis for immunoblotting, immunohistochemistry and real-time PCR analysis. To test the effects of Nox2 inhibition on behavioral outcomes, sham and septic mice were treated with $5 \mathrm{mg} / \mathrm{kg}$ of apocynin sc beginning one hour after sepsis onset and at 6, 24 and 48 hours postsepsis. Apocynin did not affect mortality or severity scores of treated mice (data not shown).

\section{Real-time PCR}

Hippocampi from sham $(n=8)$ and septic $(n=8)$ mice were directly homogenized in $1 \mathrm{ml}$ TRIzol (Invitrogen, Carlsbad, CA, USA) and total RNA was isolated following the manufacturer's suggested protocol. PCR reactions were performed, recorded, and analyzed using the Corbett Research system (Corbett Life Sciences, Sydney, Australia). The specificity of the $\mathrm{SYBR}^{\oplus}$ green assay was confirmed by melting-point analysis. Expression data were 
calculated from the cycle threshold $(\mathrm{Ct})$ value using the $\Delta \mathrm{Ct}$ method for quantification [37]. Gene expression of GAPDH mRNA (sense: 5'-GTGCAGTGCCA GCCTCGTCC-3'; antisense: 5' - CAGGCGCCCAATA CGGCCAA-3') was used for normalization. The results were expressed as percent increases. All oligonucleotides and reagents utilized in this protocol were purchased from Invitrogen, Carlsbad, CA, USA. Sequences used were: Nox2 (sense: 5'-TCAAGACCATTGCAAGTGAACAC-3'; antisense: 5'-TCAGGGCCACACAGGAAAA-3') and Nox4 (sense: 5'- TGGGCGTCCTCGGTGGAAACT-3'; antisense: 5'- TGGGTCCACAGCAGAAAACTCCA-3').

\section{Measurement of oxidative stress}

Oxidative stress was assessed by Western blotting for 4hydroxynonenal, a marker of tissue oxidative stress [38]. Mice were deeply anesthetized with isoflurane; the hippocampi were collected at different time points after sepsis induction and immediately frozen in dry ice. The tissue was homogenized in ice-cold Tris- $\mathrm{HCl}$ buffer containing protease and phosphatase inhibitor cocktails (Complete, Roche, Indianapolis, IN, USA). Protein concentration was measured with a BCA protein assay kit (Thermo Fisher Scientific, Waltham, MA, USA). Protein electrophoresis was made in Polyacrylamide 4 to $15 \%$ gradient gels (Pre-cast, BioRad, Hercules, CA, USA) and proteins were transferred to PVDF Immobillon-FL membranes (Millipore, MA, USA). Membranes were blocked with Odyssey Blocking Buffer reagent (Li-Cor Biosciences, Lincoln, NE, USA) and incubated overnight with a mouse monoclonal antibody anti-HNE (1:500, Abcam, Cambridge, MA, USA) and a rabbit polyclonal anti-cyclophilin B (1:5,000; Pierce Biotechnology, Inc. Rockford, IL, USA); the latter was used as a loading control as described elsewhere [39]. After washing with PBS, membranes were incubated with IRDye secondary antibodies (Li-Cor Biosciences) for one hour. Immunoreactivity was visualized with an Odyssey Infrared Imaging System (Li-Cor Biosciences, Lincoln, NE, USA). This system allows multiplex detection of antigens in one membrane using primary antibodies from different species, without the need for membrane stripping.

\section{Immunohistochemistry}

Mice were deeply anesthetized with isoflurane and subjected to transcardial perfusion with a saline solution followed by $4 \%$ paraformaldehyde (PFA) dissolved in $0.1 \mathrm{M} \mathrm{PBS}$ at $\mathrm{pH}$ 7.4. The brains were collected, postfixed in PFA overnight, and transferred to a $20 \%$ sucrose solution for 48 hours to ensure cryoprotection. For glial cell morphological studies, brain sections $(40 \mu \mathrm{m})$ were obtained in a cryostat (Leica Microsystems, Germany, model CM1850) and stored floating in PBS. Sections were incubated with a blocking buffer containing $0.3 \%$ Triton
X-100, 2\% normal goat serum and 1\% BSA for two hours. Sections were then incubated overnight with a rabbit IgG anti-ionized calcium binding adaptor molecule 1 (1:200; Iba1; Wako Chemicals Inc., Richmond, VA, USA) or with a rabbit IgG anti-glial fibrillary acidic protein (1:1,000; GFAP; Millipore, MA, USA) diluted in blocking buffer. Following three washes with PBS, sections were incubated for two hours with a secondary antibody, Alexa 488 goat anti-rabbit IgG diluted 1:1,000 in blocking buffer. After washing out the secondary antibody, sections were mounted on slides with Vectashield Mounting Media for Fluorescence with 4',6-diamidino-2-phenylindole (DAPI) (Vector Laboratories, Burlingame, CA, USA) for nuclear staining. Confocal images were obtained with a confocal laser-scanning microscope (Leica Microsystems, Germany, model TCS SP5 AOBS) with a 63x oil immersion objective.

For quantitative studies, $30 \mu \mathrm{m}$ brain sections were incubated free-floating for 12 to 16 hours with anti-OX42 (CD11b/c, Biosciences, San Jose, CA, USA) and antiGFAP (Immunon, Pittsburgh, PA, USA) diluted 1:1,000 in $0.3 \%$ of Triton $\mathrm{X}-100$ containing $0.05 \%$ normal goat serum. Following three washes of ten minutes each with PBS, sections were incubated for two hours with a biotinylated secondary antibody (donkey anti-mouse IgG, Jackson ImmunoResearch, West Grove, PA, USA, 1:200), followed by the avidin-biotin complex (1:100; ABC Elite kit, Vector Labs, Burlingame, CA, USA). After washing, the sections were reacted with $0.05 \% 3,3-$ diaminobenzidine and $0.01 \%$ hydrogen peroxide in PBS. Intensification was conducted with $0.05 \%$ osmium tetroxide in water. The sections were mounted on gelatinized slides, dehydrated, cleared and cover-slipped. Controls for immunostaining included the omission of the primary antibody and its substitution for normal goat serum, which completely eliminated staining. The material was analyzed using a light microscope, and digital images were semi-quantitatively analyzed using ImageJ software (National Institutes of Health, USA). OX42 and GFAP immunostaining were evaluated in terms of optical density within $0.4 \mathrm{~mm}^{2}$ areas for the CA1, CA3 and DG regions. The mean optical density of labeled areas was compared with the mean density of neighboring, nonlabeled areas in the same sections, to obtain a labeling index reflecting the mean signal-to-noise ratio as previously described [40].

\section{Behavioral tests}

Behavioral outcomes were evaluated 15 days after sepsis onset. The step-down inhibitory avoidance test was performed as we previously described [41]. In the training trial, animals were placed on a platform and their latency to step down on the grid with all four paws was measured with an automatic device. Immediately upon 
stepping down on the grid, the animals received a $0.6 \mathrm{~mA} / 3.0$-second foot shock. A retention test trial was performed 24 hours after training and duration on the grid was recorded (cut-off of 180 seconds). The Morris water maze has been extensively used to examine learning and memory deficits in many neurological disease models. Damage to the hippocampus causes impairment in spatial memory function in the water maze [42]. Animals were trained to find the platform for four days with 60 -second trial sessions and their time to find the platform was measured. On the fifth day, a trial in the absence of the platform was run and the exploration time in the quadrant where there was previously a platform was measured and expressed as latency time.

\section{MCP-1 and IL-1 measurements}

The inflammatory response induced by sepsis was evaluated by measuring the levels of monocyte chemoattractant protein (MCP)-1 and IL-1 in the plasma and in the peritoneal cavity using an ELISA method. Mice were killed in a carbon dioxide chamber six hours after sepsis onset, and the peritoneal cavity was opened and rinsed with $3 \mathrm{ml}$ of PBS solution. The peritoneal fluid was collected for determination of cytokines levels. Blood samples were collected from a peripheral vein and kept on ice. Plasma was collected by centrifugation at $800 \mathrm{~g}$ for 15 minutes at $4^{\circ} \mathrm{C}$, aliquoted, and stored at $-70^{\circ} \mathrm{C}$ until the analysis day. All measurements were performed following the manufacturer's instructions ( $R \& D$ systems Duo set kit, Minneapolis, MN, USA).

\section{Statistical analysis}

The results are presented as the mean \pm standard error of the mean (SEM). Statistical analyses of data were generated using GraphPad Prism, version 3.02 (GraphPad Software Inc., San Diego, CA, USA). Statistical comparisons of more than two groups were performed using an analysis of variance (ANOVA) and were analyzed by the Mann-Whitney $U$-test or the Kruskal-Wallis test. In all cases, $P \leq 0.05$ was considered statistically significant.

\section{Results}

Oxidative stress in the hippocampus is associated with Nox2 expression

To evaluate oxidative damage in the hippocampus of septic mice, we measured the expression of 4-hydroxynonenal (4HNE), a by-product of lipid peroxidation. We observed a progressive increase in 4-HNE levels in the hippocampus early after sepsis that was accompanied by a significant increase in Nox2 gene expression. 4-HNE was detected at six hours, twenty-four hours, and up to five days post-sepsis (Figure 1A). Real-time PCR analysis revealed that Nox2 gene expression was significantly induced in the hippocampus at twenty-four hours and five days, while Nox4 was not significantly changed, indicating that Nox2 is associated with brain oxidative stress in SAE (Figure 1B, C). To clarify the role of Nox2 in the oxidative damage in SAE, we treated mice with apocynin. The treatment with apocynin prevented the 4-HNE increase in the hippocampus induced by sepsis (Figure 2A), indicating that Nox2 must be a major contributor to hippocampal ROS generation in SAE.

\section{Apocynin modulates neuroinflammation in sepsis- associated encephalopathy (SAE) by inhibiting astrogliosis}

Six hours after sepsis onset there is already a significant activation of astrocytes and microglia in WT animals. Activated microglia presented increased Iba1 immunoreactivity and hypertrophic morphology (Figure 2B). Astrocytes activation presented thickening of cellular processes and increased expression of GFAP (Figure 2C). Astrocytes and microglia were affected in different ways by apocynin treatment. Astrocyte activation was inhibited by apocynin, whereas microglia activation was not affected (Figure 2).

Microglia and astrocyte activation were more pronounced five days after sepsis onset, so we performed quantification of glial cells activation in different regions of the hippocampus at this time point to confirm the morphological findings. Microglial activation was more prominent within the CA1 and DG regions (CA1 circa 146\%; CA3 circa 73\%; and DG circa 151\%). Apocynin treatment was not able to prevent microglial activation induced by sepsis in CA1, CA3 and DG (Figures 3A, B, $\mathrm{C}$ and $4 \mathrm{~A})$. Septic mice exhibited a significant increase in the number of activated astrocytes with highly ramified and thick processes (CA1 circa 87\%; CA3 circa 163\%; and DG circa 166\% versus control). The treatment with apocynin reversed astrocyte activation in all of the hippocampal regions analyzed (CA1 circa 56\%; CA3 circa 63\%; and DG circa 56\%, Figures 3D, E, F and 4B).

\section{Neuroinflammation induced by sepsis- associated encephalopathy (SAE) is impaired in Nox2 knockout mice} To further investigate the role of Nox 2 in glial cell activation, we used gp91 ${ }^{\text {phox-/- }}$ mice and evaluated astrocyte and microglia activation in different regions of the hippocampus five days after sepsis. We observed no discernible differences in CD11b or GFAP immunostaining between sham gp91 $1^{\text {phox-/- }}$ and septic gp91 ${ }^{\text {phox-/- }}$ mice (Figure 5). These results indicate that, although apocynin treatment did not prevent microglia activation, a functional Nox2 was necessary for microglia activation in SAE. Astrocyte activation induced by sepsis was also impaired in $\mathrm{gp} 91^{\text {phox-/- }}$ mice, indicating a complete dependence of astrocytes on Nox2 in order to become activated (Figure 5). 


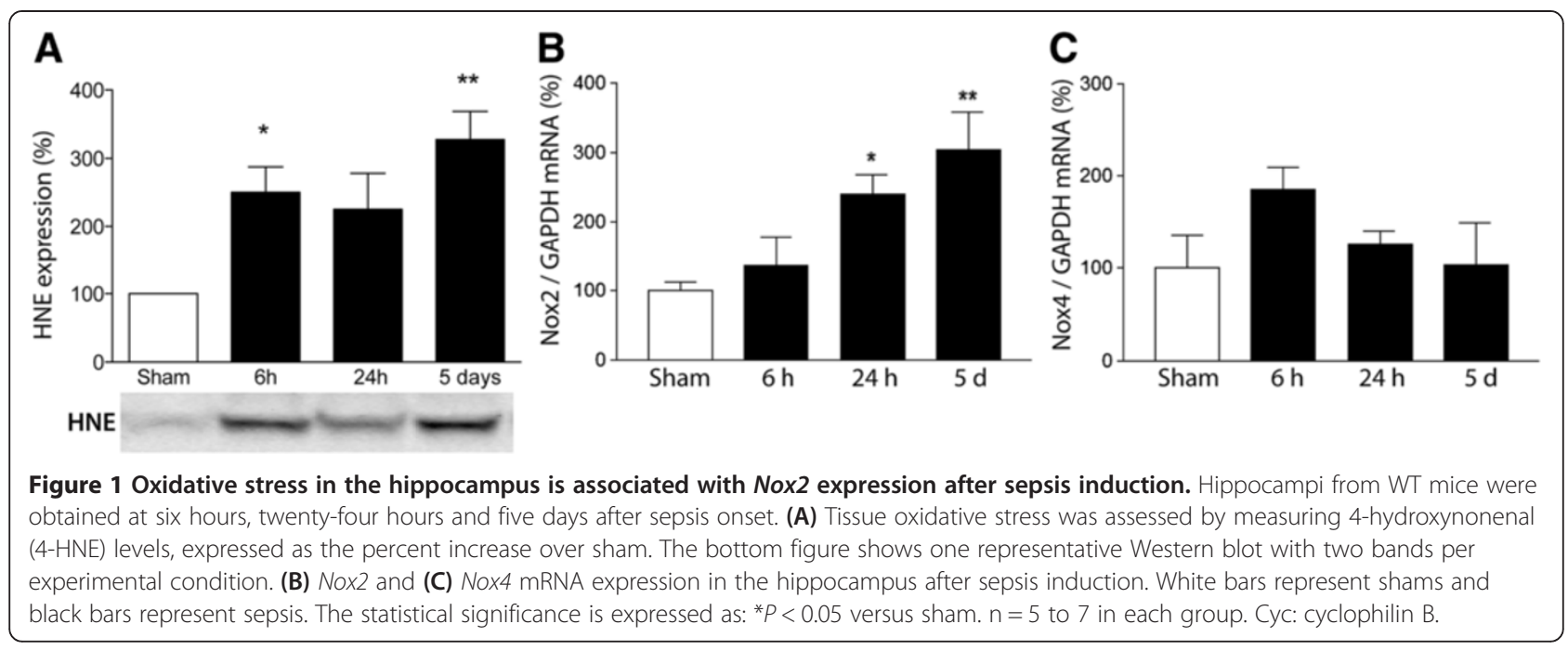

Acute apocynin treatment prevents long-term cognitive impairment after sepsis

To test the hypothesis that Nox-derived oxidative stress determines behavioral outcomes in sepsis survivors, we treated animals with low doses of apocynin $(5 \mathrm{mg} / \mathrm{kg})$ throughout the acute phase of sepsis and performed behavioral tests to evaluate cognitive function in survivors fifteen days after sepsis onset. Mice that survived sepsis presented significantly lower latency time on the inhibitory avoidance test, but septic mice treated with

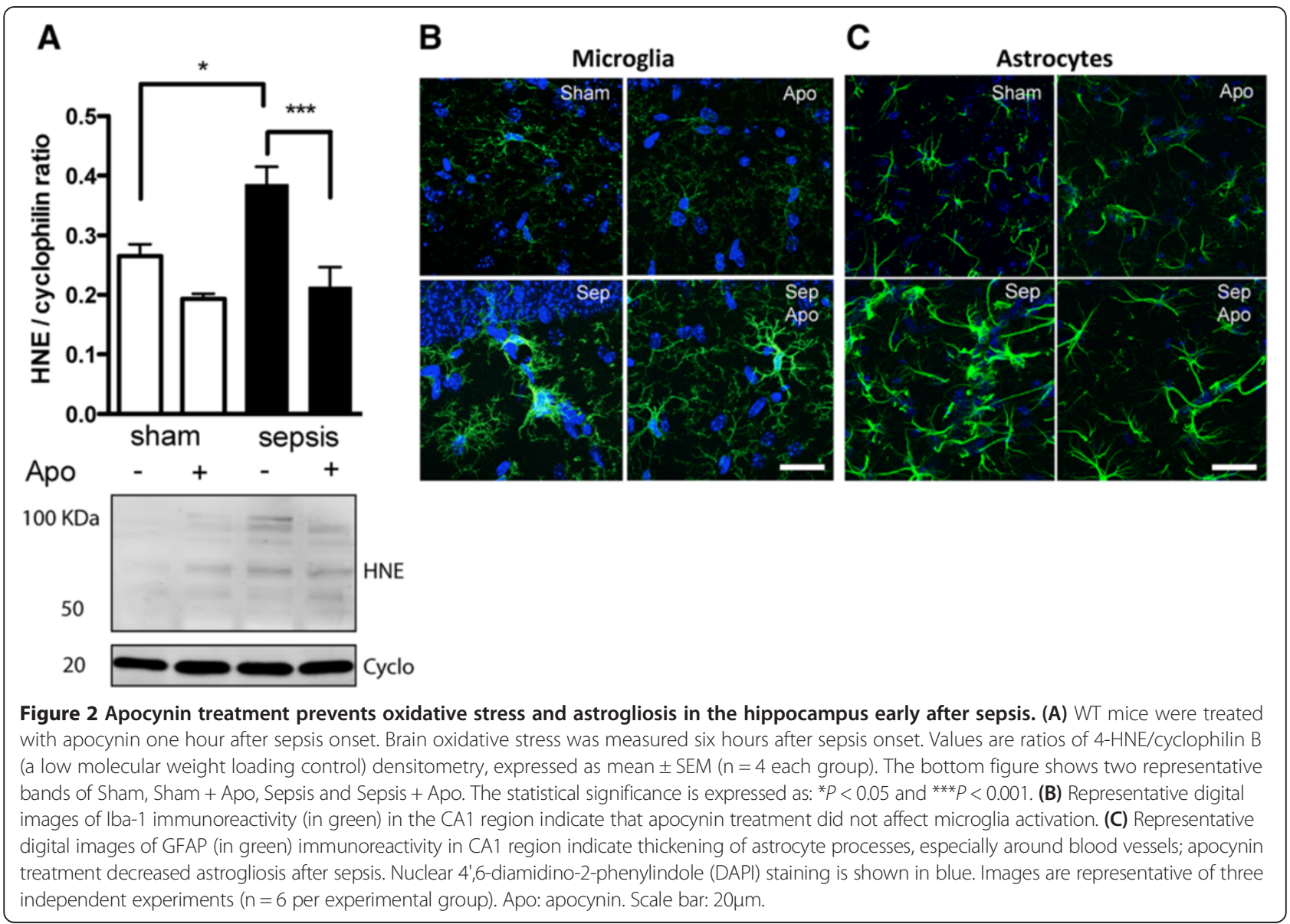



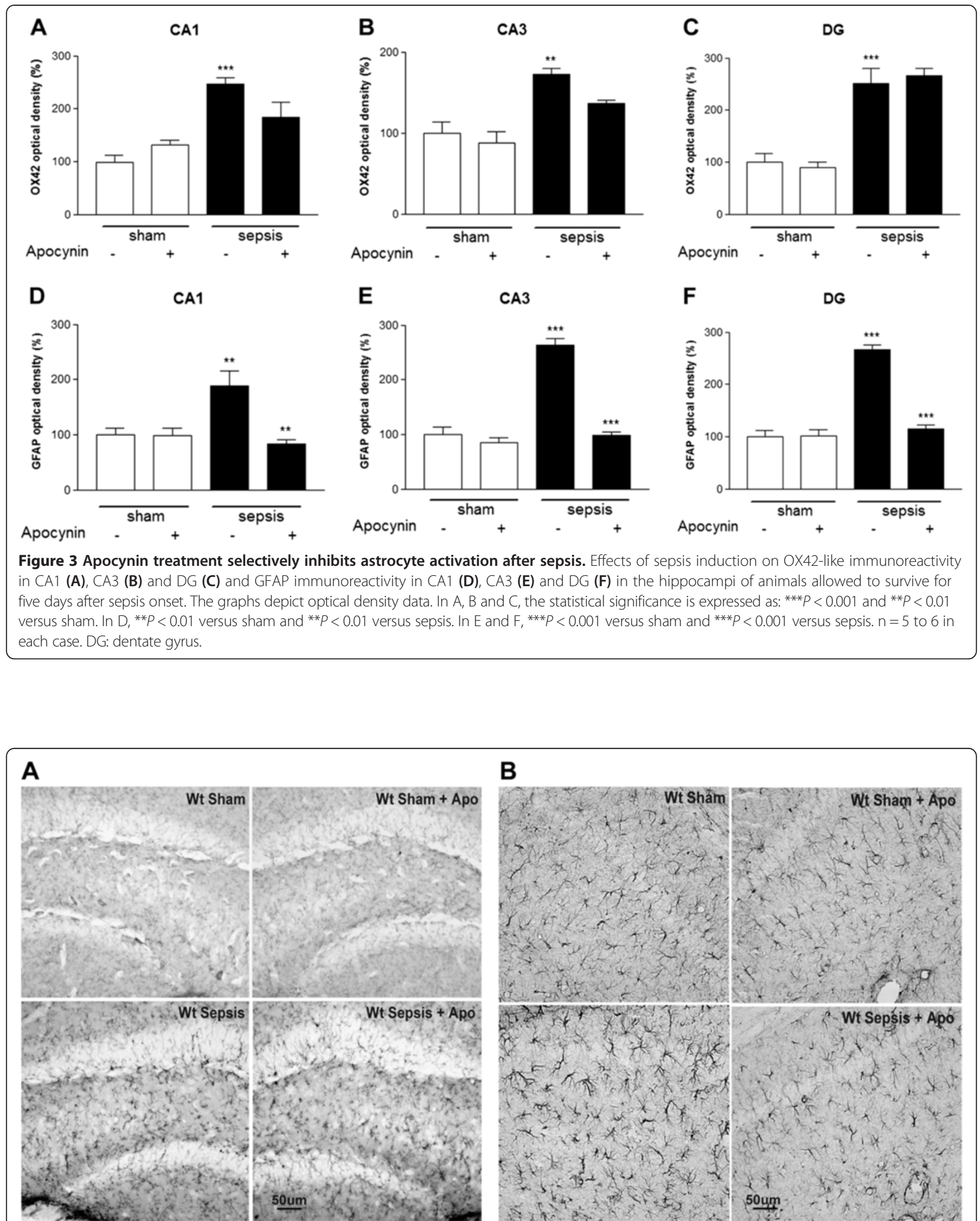

B

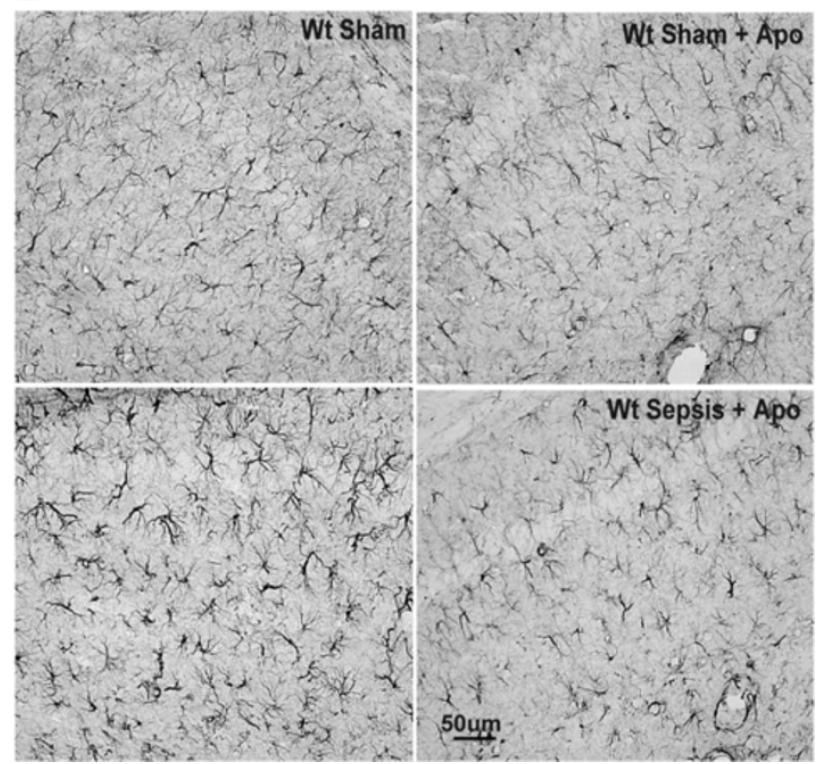

Figure 4 Apocynin inhibits astrogliosis in the dentate gyrus of the hippocampus. Representative digital images of OX42-like immunoreactivity (A) and GFAP-like immunoreactivity (B) in the dentate gyrus (DG) of the WT Sham, WT Sham apocynin, WT Sepsis, WT Sepsis apocynin groups analyzed five days after sepsis onset. 


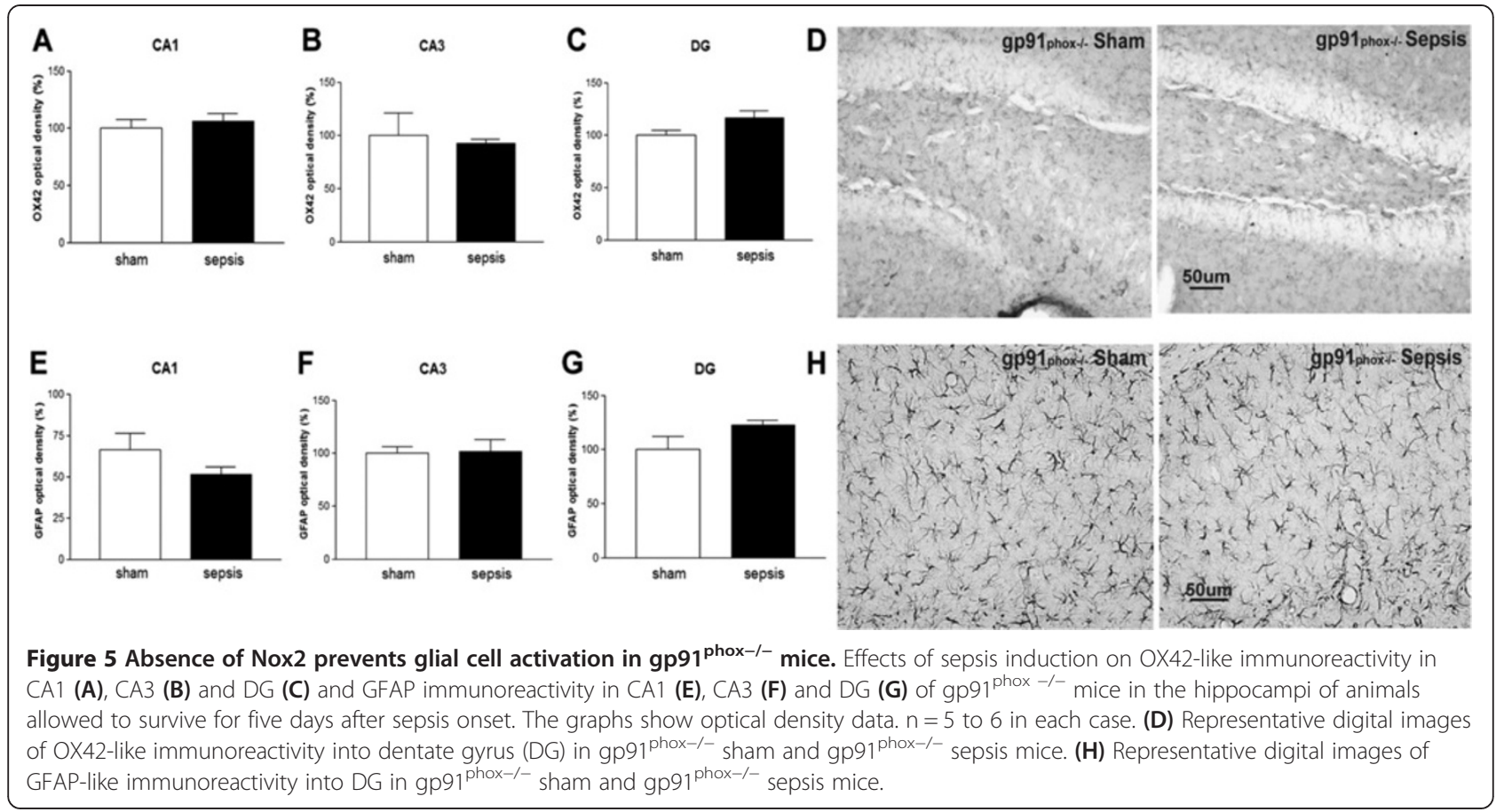

apocynin did not show any memory deficits in this test (Figure 6A). In the Morris water maze test, sepsis survivors presented an increase in the time to find the platform (Figure 6B) and spent less time in the right quadrant (Figure 6C), whereas sham animals and apocynin-treated mice all had better performances in both tests (Figure 6). These results indicate that Nox2derived oxidative damage to the hippocampus is an important factor implicated in the long-term cognitive impairment associated with sepsis.

\section{Systemic inflammation induced by sepsis is not} decreased by the pharmacological inhibition of Nox2

In order to investigate whether the protective effects observed by the pharmacological inhibition of Nox 2 on oxidative stress, neuroinflammation and in the development

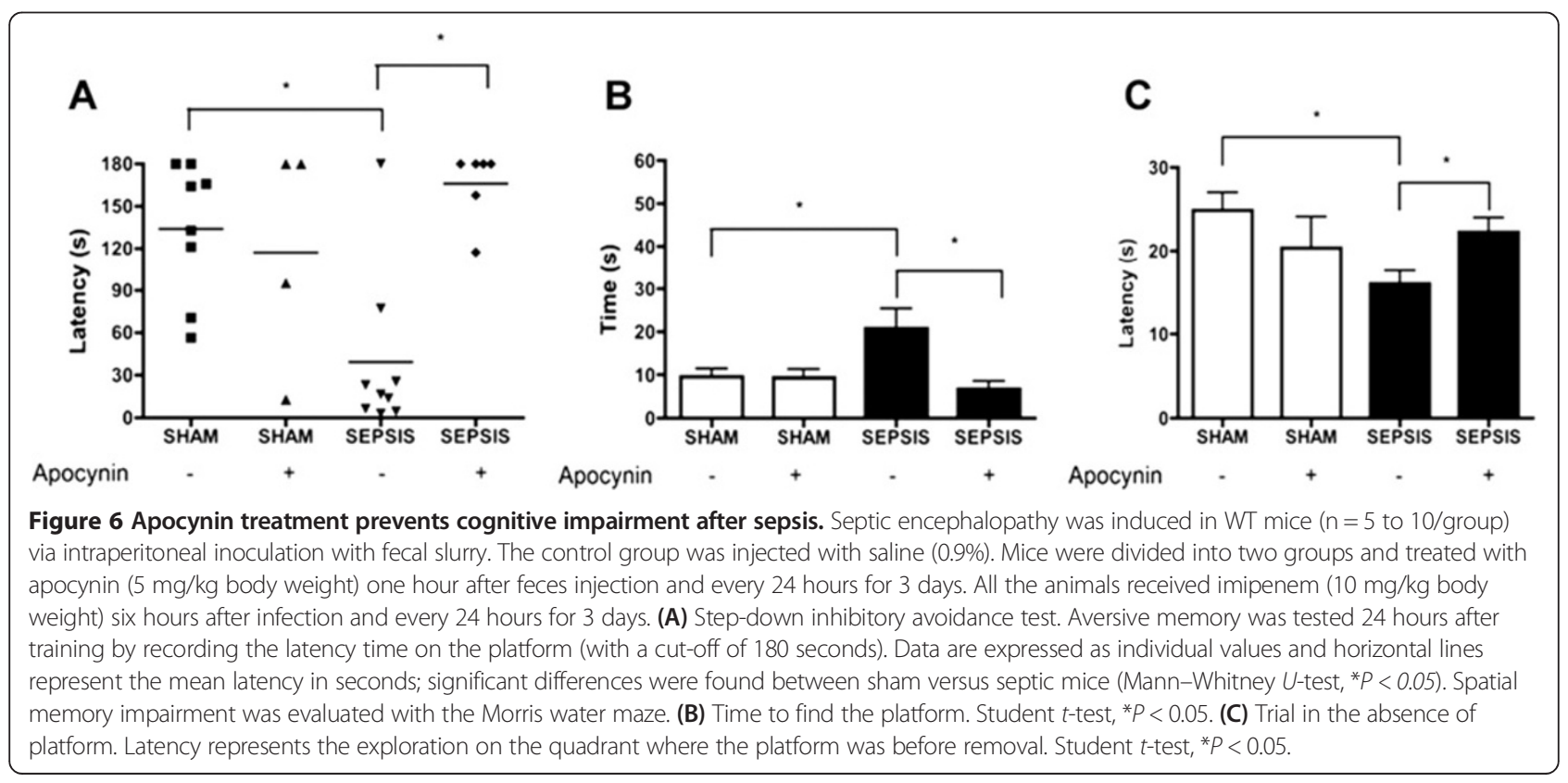


of long-term cognitive impairment were secondary to a decreased systemic inflammation, animals were treated with apocynin and cytokines levels were measured after sepsis induction. We specifically investigated the ability of apocynin to decrease MCP-1 and IL-1 levels in plasma and in peritoneal fluid six hours after sepsis onset. As shown in Figure $7 \mathrm{~A}$ and $\mathrm{B}$, we observed a significant increase in MCP-1 levels in both plasma and in peritoneal fluid after sepsis onset, which was not inhibited by apocynin treatment. IL-1 levels were found significantly increased only in peritoneal fluid (Figures 7C and D). Similarly, apocynin treatment was not able to significantly inhibit IL-1 increased levels. These results suggest that the apocynin treatment was not able to prevent systemic inflammation induced by sepsis as opposed as its central effects.

\section{Discussion}

The results presented in this study provide evidence that Nox2 is the main source of ROS involved in the oxidative damage to the hippocampus in SAE and that Nox2derived ROS are determining factors for cognitive impairments after sepsis. There are numerous experimental findings that support these conclusions. First, there is a progressive oxidative damage to the hippocampus, identified by increased 4-HNE expression, associated with an increase in Nox2 gene expression in the first days after sepsis. Second, pharmacological inhibition of Nox2 with apocynin completely inhibits hippocampal oxidative damage in septic animals. Third, pharmacological inhibition or the absence of Nox2 in gp91 ${ }^{\text {phox-l- }}$ mice prevents glial cell activation, one of the central mechanisms associated with SAE and other neurodegenerative diseases [43-45]. Finally, treatment with apocynin in the acute phase of sepsis prevents the development of long-term cognitive impairment in the survivors. Our results confirm previous findings that oxidative damage to the hippocampus is involved in the development of cognitive impairment in SAE. These results also highlight the importance of Nox2-derived ROS as a central mechanism in glial cells activation and identify Nox2 as a potential target for future therapies to prevent SAE.

Sepsis-induced organ dysfunction has been attributed to a tissue adaptation to systemic inflammation, which involves mitochondrial dysfunction, oxidative stress and bioenergetics impairments [46,47]. Evidence from the
A

plasma

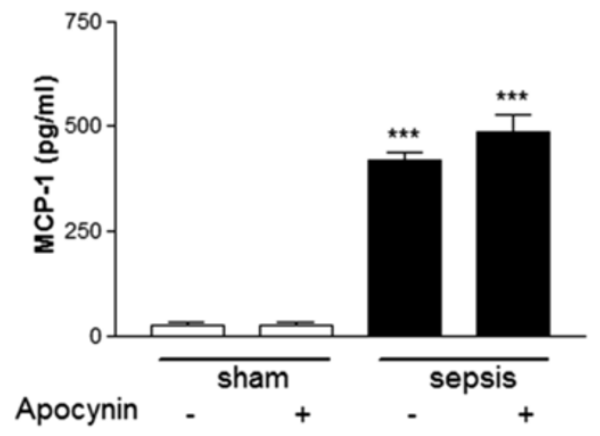

C

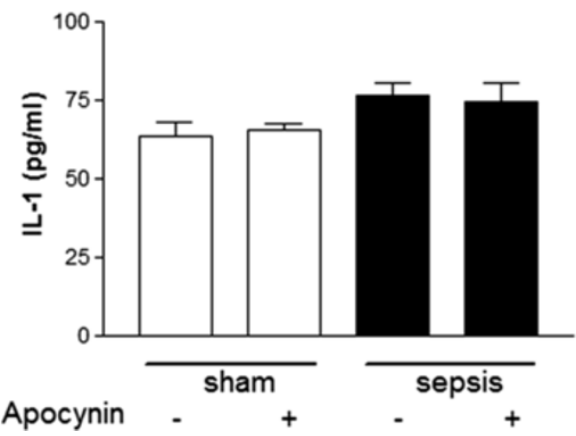

B

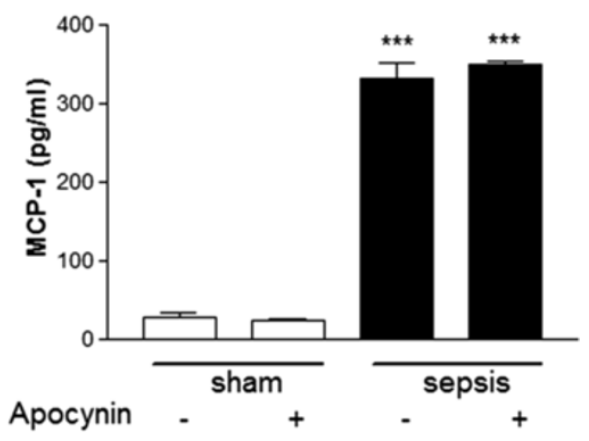

D

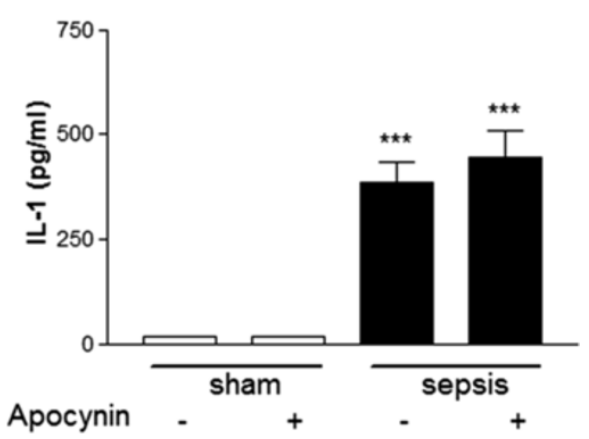

Figure 7 Systemic inflammation induced by sepsis is not affected by the pharmacological inhibition of Nox2. Effects of sepsis induction on MCP-1 and IL-1 levels in the plasma and peritoneal fluid of WT animals treated with apocynin. Mice were allowed to survive for six hours after sepsis onset. All concentrations were expressed in $\mathrm{pg} / \mathrm{ml}$. The statistical significance is expressed as: ${ }^{* *} P<0.001 ; n=6$ to 10 for each experimental group tested. 
literature supports the hypothesis that alterations in mitochondrial function may increase $\mathrm{O}^{--}$generation as a byproduct of the electron transport chain, especially O2 ${ }^{--}$derived from complex I [48-50]. However, the role of complex I as the major site of ROS production in intact mitochondria in the absence of respiratory chain inhibitors remain controversial. Previous studies from our group demonstrated a reduction in oxidative phosphorylation efficiency and complex IV activity in brain tissue 24 hours after sepsis onset in the CLP mouse model. In this study, we were not able to detect mitochondrial ROS production [47], suggesting that other pathways could be responsible for the oxidative stress observed in the brain tissue of septic rodents [9].

Increased NADPH oxidase activity has been implicated in a variety of neurodegenerative conditions, such as Parkinson's and Alzheimer's diseases (reviewed by $[23,29])$. There is increasing evidence that aldehyde molecules generated endogenously during the process of lipid peroxidation, such as 4-HNE, are causally involved in most of the pathophysiological effects associated with oxidative stress in vivo [38]. Therefore, we hypothesized that ROS derived from NADPH oxidase is the main cause of oxidative stress and brain dysfunction after sepsis. To test this hypothesis, we used pharmacological inhibition of NADPH oxidase and genetic deletion of the catalytic subunit gp $91^{\text {phox }}$ to evaluate the acute and long-term outcomes of sepsis. Our data show that 4HNE levels are increased in the brains of septic mice, beginning six hours and up to five days post-sepsis.
Real-time PCR analysis demonstrated that Nox2, but not Nox4 mRNA, was induced in the hippocampus 24 hours after sepsis, whereas oxidative stress was detected earlier at six hours, suggesting that NADPH oxidase activity is induced before the increase in gene expression. Treatment with apocynin inhibited the oxidative stress at six hours, indicating that it might be caused by an increase in Nox2 enzyme activity. Apocynin reacts with the cysteine residues of $\mathrm{p} 47^{\mathrm{phox}}$, a cytosolic component of the complex, inhibiting its association with the Nox2p $22^{\text {phox }}$ heterodimer and, consequently, its enzyme activity. The early increase in NADPH oxidase activity followed by an increase in gene expression has been demonstrated in other models of acute brain injury [51]. Thus, our data add to previous observations that mitochondria are not the main source of ROS in the nervous system after sepsis induction, and a significant portion of ROS production in the hippocampus under septic conditions is attributable to Nox2.

Nox2 has been shown to regulate intracellular ROS levels in microglia and to result in both amplification of pro-inflammatory cytokines production and priming of microglia to additional stimuli [52]. In vitro studies suggested that the production of ROS from Nox2 is also essential for the morphological activation of microglia in both 6-hydroxidopamine and lipopolysaccharide (LPS)Parkinson's disease models [53-55]. Our immunohistochemistry data show the absence of microglia activation in gp $91^{\text {phox-/- }}$ after sepsis induction, consistent with the essential role of Nox2 in signaling microglia activation.

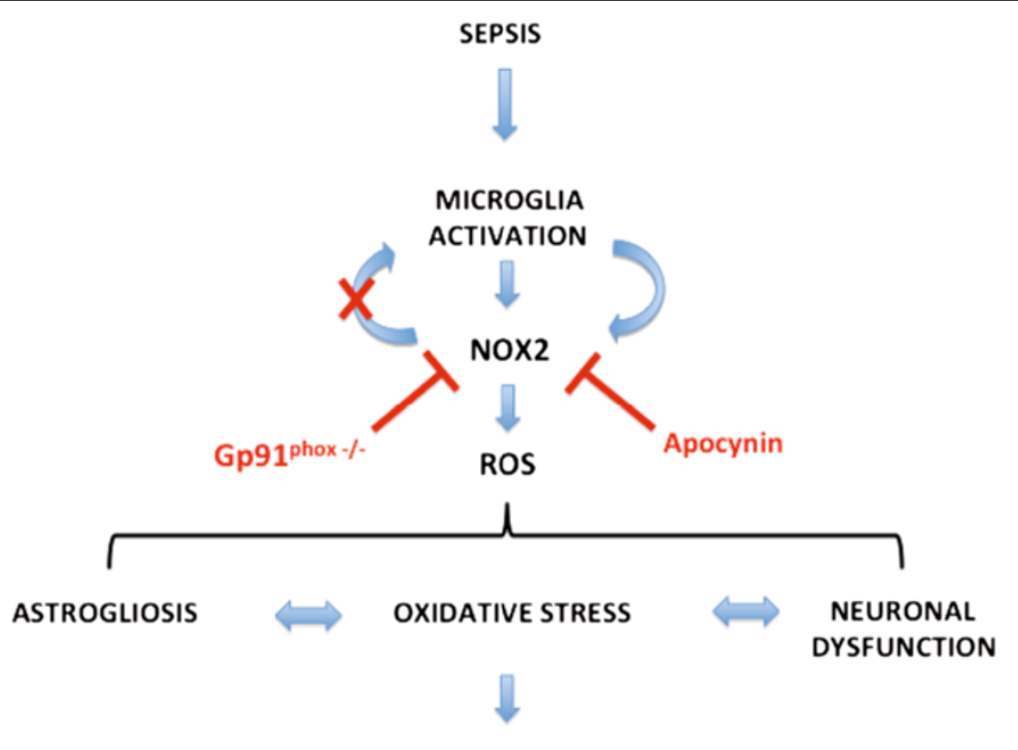

NEUROLOGICAL OUTCOMES, COGNITIVE IMPAIRMENT

Figure 8 Summary of the main findings. This figure highlights the involvement of Nox2 in brain dysfunction associated to sepsis- associated encephalopathy (SAE) and the long-term consequences. Nox2 activation is inhibited by apocynin, preventing ROS production without affecting microglial activation. Gp91 ${ }^{\text {phox }}$ gene deletion impairs microglial activation after sepsis. 
Nevertheless, microglial activation was not prevented by the NADPH oxidase inhibitor apocynin. One possibility to explain this finding is that apocynin treatment does not inhibit microglia activation, but alters its phenotype to an anti-inflammatory M2-like phenotype, as recently demonstrated by Choi and colleagues [56].

In contrast, astrocyte activation after sepsis was significantly inhibited by a single dose of apocynin, suggesting that Nox2-derived ROS played a role in the signaling events leading to astrocyte activation after sepsis. Similarly, it has been shown that ischemic animals treated with apocynin showed significantly less reactive astrocytes compared to the non-treated group [57]. NADPH oxidase activation in astrocytes may lead to oxidative stress, glutathione depletion, and neuronal death $[58,59]$.

Patients with chronic granulomatous disease (CGD), an immunodeficiency syndrome caused by disabling mutations of genes encoding the NADPH oxidase subunits $[60,61]$, have an increased susceptibility to fungal and bacterial infections. Pre-clinical models using NADPH oxidase-deficient mice [62,63] have shown intrinsic defects in the control of inflammation. Han et al. (2013) demonstrated that $\mathrm{p} 47^{\text {phox-1- }}$ mice have increased lung inflammation after LPS instillation and that this effect is due to increased NF- $\kappa B$ binding to DNA [64]. Therefore, inhibition of NADPH oxidase may be protective to the central nervous system, but may have deleterious effects in the control of systemic inflammation and/or infection. It is important to note that this does not seem to be the case in our study, because we did not observe increased mortality in apocynin-treated animals (data not shown) and in the inflammatory response induced by sepsis (as demonstrated by the evaluation of proinflammatory cytokines levels); this outcome may be explained by the low doses used to block NAPDH oxidase in our conditions.

Although there is enough evidence from the literature that sepsis survivors develop cognitive impairments, the molecular mechanisms of cognitive impairment in sepsis are far from understood. Several hypotheses were created to explain the brain dysfunction associated with sepsis, including neuroinflammation, neurotransmitter disturbances, apoptosis, and oxidative stress. Evidence from animal studies links oxidative damage and longterm cognitive impairment. Barichello et al. (2007) demonstrated that the administration of a combination of antioxidants, $\mathrm{N}$-acetylcysteine plus deferoxamin, in the acute phase of sepsis prevented long-term oxidative damage [65]. In our study, we demonstrated that Nox2-derived ROS are determinants of neuroinflammation and of the development of long-term cognitive impairment. Strategies to modulate Nox2 activity may be useful in the future to prevent SAE development (Figure 8).

\section{Conclusions}

The results of the present study demonstrate that Nox2 is essential for glial cell activation and emphasize the critical role of oxidative damage and Nox2-derived ROS as central factors contributing to acute and long-term brain dysfunction after sepsis.

\section{Abbreviations}

GFAP: glial fibrilary acidic proteins; HNE: hydroxynonenal; Iba-1: ionized calcium binding adaptor molecule 1; LPS: lipopolysaccharide; NADPH: nicotinamide adenine dinucleotide phosphate; ROS: reactive oxygen species; SAE: sepsisassociated encephalopathy.

\section{Competing interests}

The authors declare that they have no competing interests.

\section{Authors' contributions}

MSH PhD: performed histological assessments, data analysis, and drafted the manuscript. JCd'A PhD: performed histological and biochemical assessments, data analysis, and final manuscript preparation. SCT MSc: performed animal surgeries and data analysis. PAR PhD: performed and analyzed the behavioral studies. ERK PhD: performed experiments. LRL PhD: supervised overall project. HCC-F-N MD, PhD: supervised behavioral studies and assisted in manuscript preparation. FQC PhD: supervised animal surgeries and designed studies. LRGB PhD: designed studies, supervised histological assessments and assisted in manuscript preparation. FAB MD PhD: designed studies, supervised overall project and final manuscript preparation. All authors have read and approved the final version of the manuscript.

\section{Acknowledgments}

We thank Professor Rui Curi for supplying gp91 ${ }^{\text {phox-l- }}$ mice. We also thank Adilson S Alves for technical assistance.

\section{Grant information}

Work supported by FAPERJ (Fundação de Amparo à Pesquisa do Estado do Rio de Janeiro), FAPESP (Fundação de Amparo à Pesquisa do Estado de São Paulo), University of São Paulo-NAPNA and CNPq (Conselho Nacional de Desenvolvimento Científico e Tecnológico). JCD and FAB were the recipients of fellowships from FAPERJ. MSH and SCT were the recipients of fellowships from FAPESP. ERK and FAB were recipients of fellowships from CNPq.

\section{Author details}

${ }^{1}$ Department of Physiology and Biophysics, University of São Paulo, São Paulo, Brazil. '2Department of Pharmacology, Institute of Biomedical Sciences, University of São Paulo, São Paulo, Brazil. 'Laboratório de Imunofarmacologia, Instituto Oswaldo Cruz, FIOCRUZ, Rio de Janeiro, Brazil. ${ }^{4}$ Department of Pharmacology, Faculty of Medicine of Ribeirão Preto, University of São Paulo, Ribeirão Preto, São Paulo, Brazil. ${ }^{5}$ Instituto de Pesquisa Clínica Evandro Chagas, FIOCRUZ, e Instituto D'Or de Pesquisa e Ensino (IDOR), Rio de Janeiro, Brazil. ${ }^{6}$ Laboratory of Cellular Neurobiology, Institute of Biomedical Sciences, University of São Paulo, Av. Professor Lineu Prestes, 1524, ZIP: 05508-900 São Paulo, Brazil. 'Intensive Care Unit, Instituto de Pesquisa Clinica Evandro Chagas, Fundação Oswaldo Cruz, Av. Brasil, 4365, Rio de Janeiro RJ ZIP: 21040-900, Brazil.

Received: 24 September 2013 Accepted: 30 January 2014 Published: 27 February 2014

\section{References}

1. Ebels EJ: latrogenic damage to the central nervous system in malignant systemic disease. Acta Neuropathol Supp/ 1981, 7:352-355.

2. Forbes GB: Neurologic complications of systemic disease. Postgrad Med 1954, 15(2):157-162.

3. Young RS, Yagel SK, Towfighi J: Systemic and neuropathologic effects of E. coli endotoxin in neonatal dogs. Pediatr Res 1983, 17(5):349-353.

4. Eidelman LA, Putterman D, Putterman C, Sprung CL: The spectrum of septic encephalopathy. Definitions, etiologies, and mortalities. JAMA 1996, 275(6):470-473. 
5. Iwashyna TJ, Ely EW, Smith DM, Langa KM: Long-term cognitive impairment and functional disability among survivors of severe sepsis. JAMA 2010, 304(16):1787-1794.

6. Adam N, Kandelman S, Mantz J, Chretien F, Sharshar T: Sepsis-induced brain dysfunction. Expert Rev Anti Infect Ther 2013, 11(2):211-221.

7. Comim CM, Cassol-Jr OJ, Constantino LS, Felisberto F, Petronilho F, Rezin GT, Scaini G, Daufenbach JF, Streck EL, Quevedo J, Dal-Pizzol F: Alterations in inflammatory mediators, oxidative stress parameters and energetic metabolism in the brain of sepsis survivor rats. Neurochem Res 2011, 36(2):304-311.

8. Gomes RN, Teixeira-Cunha MG, Figueiredo RT, Almeida PE, Alves SC, Bozza PT, Bozza FA, Bozza MT, Zimmerman GA, Castro-Faria-Neto HC: Bacterial clearance in septic mice is modulated by MCP-1/CCL2 and nitric oxide. Shock 2013, 39(1):63-69.

9. Barichello T, Fortunato JJ, Vitali AM, Feier G, Reinke A, Moreira JC, Quevedo J, Dal-Pizzol F: Oxidative variables in the rat brain after sepsis induced by cecal ligation and perforation. Crit Care Med 2006, 34(3):886-889.

10. Berg RM, Moller K, Bailey DM: Neuro-oxidative-nitrosative stress in sepsis. J Cereb Blood Flow Metab 2011, 31(7):1532-1544.

11. Ritter C, Andrades M, Frota Junior ML, Bonatto F, Pinho RA, Polydoro M, Klamt F, Pinheiro CT, Menna-Barreto SS, Moreira JC, Dal-Pizzol F: Oxidative parameters and mortality in sepsis induced by cecal ligation and perforation. Intensive Care Med 2003, 29(10):1782-1789.

12. Borrelli E, Roux-Lombard P, Grau GE, Girardin E, Ricou B, Dayer J, Suter PM: Plasma concentrations of cytokines, their soluble receptors, and antioxidant vitamins can predict the development of multiple organ failure in patients at risk. Crit Care Med 1996, 24(3):392-397.

13. Chuang CC, Shiesh SC, Chi CH, Tu YF, Hor LI, Shieh CC, Chen MF: Serum total antioxidant capacity reflects severity of illness in patients with severe sepsis. Crit Care 2006, 10(1):R36.

14. Goode HF, Cowley HC, Walker BE, Howdle PD, Webster NR: Decreased antioxidant status and increased lipid peroxidation in patients with septic shock and secondary organ dysfunction. Crit Care Med 1995, 23(4):646-651

15. Huet O, Obata R, Aubron C, Spraul-Davit A, Charpentier J, Laplace C, Nguyen-Khoa T, Conti M, Vicaut E, Mira JP, Duranteau J: Plasma-induced endothelial oxidative stress is related to the severity of septic shock. Crit Care Med 2007, 35(3):821-826.

16. Guerreiro MO, Petronilho F, Andrades M, Constantino L, Mina FG, Moreira JC Dal-Pizzol F, Ritter C: Plasma superoxide dismutase activity and mortality in septic patients [corrected]. J Trauma 2010, 69(6):E102-E106

17. Cowley HC, Bacon PJ, Goode HF, Webster NR, Jones JG, Menon DK: Plasma antioxidant potential in severe sepsis: a comparison of survivors and nonsurvivors. Crit Care Med 1996, 24(7):1179-1183.

18. West AP, Shadel GS, Ghosh S: Mitochondria in innate immune responses. Nat Rev Immunol 2011, 11(6):389-402.

19. Sena LA, Li S, Jairaman A, Prakriya M, Ezponda T, Hildeman DA, Wang CR, Schumacker PT, Licht JD, Perlman H, Bryce PJ, Chandel NS: Mitochondria are required for antigen-specific $T$ cell activation through reactive oxygen species signaling. Immunity 2013, 38(2):225-236.

20. Nohl H, Kozlov AV, Gille L, Staniek K: Cell respiration and formation of reactive oxygen species: facts and artefacts. Biochem Soc Trans 2003 31(Pt 6):1308-1311.

21. Babior BM: NADPH oxidase: an update. Blood 1999, 93(5):1464-1476.

22. Babior BM: The activity of leukocyte NADPH oxidase: regulation by p47PHOX cysteine and serine residues. Antioxid Redox Signal 2002, 4(1):35-38.

23. Hernandes MSBL: NADPH oxidase and neurodegeneration. Curr Neuropharmacol 2012, 10(4):321-327.

24. Bedard K, Krause KH: The NOX family of ROS-generating NADPH oxidases: physiology and pathophysiology. Physiol Rev 2007, 87(1):245-313.

25. Yoshioka H, Niizuma K, Katsu M, Okami N, Sakata H, Kim GS, Narasimhan P, Chan PH: NADPH oxidase mediates striatal neuronal injury after transient global cerebral ischemia. J Cereb Blood Flow Metab 2011, 31(3):868-880.

26. Suh SW, Shin BS, Ma H, Van Hoecke M, Brennan AM, Yenari MA, Swanson RA: Glucose and NADPH oxidase drive neuronal superoxide formation in stroke. Ann Neurol 2008, 64(6):654-663.

27. Sugawara $\mathrm{T}$, Chan $\mathrm{PH}$ : Reactive oxygen radicals and pathogenesis of neuronal death after cerebral ischemia. Antioxid Redox Signal 2003, 5(5):597-607.

28. Brennan AM, Suh SW, Won SJ, Narasimhan P, Kauppinen TM, Lee $H_{4}$ Edling $Y$, Chan PH, Swanson RA: NADPH oxidase is the primary source of superoxide induced by NMDA receptor activation. Nat Neurosci 2009, 12(7):857-863.

29. Sorce $\mathrm{S}$, Krause KH: NOX enzymes in the central nervous system: from signaling to disease. Antioxid Redox Signal 2009, 11(10):2481-2504.

30. Alves-Filho JC, Freitas A, Souto FO, Spiller F, Paula-Neto H, Silva JS, Gazzinelli RT, Teixeira MM, Ferreira SH, Cunha FQ: Regulation of chemokine receptor by Toll-like receptor 2 is critical to neutrophil migration and resistance to polymicrobial sepsis. Proc Natl Acad Sci USA 2009, 106(10):4018-4023.

31. Simons JM, Hart BA, Ip Vai Ching TR, Van Dijk H, Labadie RP: Metabolic activation of natural phenols into selective oxidative burst agonists by activated human neutrophils. Free Radic Biol Med 1990, 8(3):251-258.

32. Ghosh A, Kanthasamy A, Joseph J, Anantharam V, Srivastava P, Dranka BP, Kalyanaraman B, Kanthasamy AG: Anti-inflammatory and neuroprotective effects of an orally active apocynin derivative in pre-clinical models of Parkinson's disease. J Neuroinflammation 2012, 9:241.

33. Stolk J, Hiltermann TJ, Dijkman JH, Verhoeven AJ: Characteristics of the inhibition of NADPH oxidase activation in neutrophils by apocynin, a methoxy-substituted catechol. Am J Respir Cell Mol Biol 1994, 11(1):95-102.

34. Lafeber FP, Beukelman CJ, van den Worm E, van Roy JL, Vianen ME, van Roon JA, van Dijk H, Bijlsma JW: Apocynin, a plant-derived, cartilage-saving drug, might be useful in the treatment of rheumatoid arthritis. Rheumatology (Oxford) 1999, 38(11):1088-1093.

35. Boillee S, Cleveland DW: Revisiting oxidative damage in ALS: microglia, Nox, and mutant SOD1. J Clin Invest 2008, 118(2):474-478.

36. Chen $\mathrm{H}$, Song YS, Chan PH: Inhibition of NADPH oxidase is neuroprotective after ischemia-reperfusion. J Cereb Blood Flow Metab 2009, 29(7):1262-1272.

37. Dussault AA, Pouliot M: Rapid and simple comparison of messenger RNA levels using real-time PCR. Biol Proced Online 2006, 8:1-10.

38. Uchida K: 4-hydroxy-2-nonenal: a product and mediator of oxidative stress. Prog Lipid Res 2003, 42(4):318-343.

39. Sebollela A, Freitas-Correa L, Oliveira FF, Paula-Lima AC, Saraiva LM, Martins SM, Mota LD, Torres C, Alves-Leon S, de Souza JM, Carraro DM, Brentani H, De Felice FG, Ferreira ST: Amyloid-beta oligomers induce differential gene expression in adult human brain slices. J Biol Chem 2012, 287(10):7436-7445.

40. Hernandes MS, Britto LR, Real CC, Martins DO, Lopes LR: Reactive oxygen species and the structural remodeling of the visual system after ocular enucleation. Neuroscience 2010, 170(4):1249-1260.

41. Reis PA, Comim CM, Hermani F, Silva B, Barichello T, Portella AC, Gomes FC, Sab IM, Frutuoso VS, Oliveira MF, Bozza PT, Bozza FA, Dal-Pizzol F, Zimmerman GA, Quevedo J, Castro-Faria-Neto HC: Cognitive dysfunction is sustained after rescue therapy in experimental cerebral malaria, and is reduced by additive antioxidant therapy. PLoS Pathog 2010, 6(6):e1000963.

42. Morris RG, Garrud P, Rawlins JN, O'Keefe J: Place navigation impaired in rats with hippocampal lesions. Nature 1982, 297(5868):681-683.

43. Brown DI, Griendling KK: Nox proteins in signal transduction. Free Radic Biol Med 2009, 47(9):1239-1253.

44. Ransohoff RM, Brown MA: Innate immunity in the central nervous system. J Clin Invest 2012, 122(4):1164-1171.

45. Sharshar T, Annane D, de la Grandmaison GL, Brouland JP, Hopkinson NS, Francoise G: The neuropathology of septic shock. Brain Pathol 2004, 14(1):21-33.

46. Crouser ED, Julian MW, Blaho DV, Pfeiffer DR: Endotoxin-induced mitochondrial damage correlates with impaired respiratory activity. Crit Care Med 2002, 30(2):276-284.

47. D'Avila JC, Santiago AP, Amancio RT, Galina A, Oliveira MF, Bozza FA: Sepsis induces brain mitochondrial dysfunction. Crit Care Med 2008 36(6):1925-1932.

48. Barja G: Mitochondrial oxygen radical generation and leak: sites of production in states 4 and 3, organ specificity, and relation to aging and longevity. J Bioenerg Biomembr 1999, 31(4):347-366.

49. Barja G, Herrero A: Oxidative damage to mitochondrial DNA is inversely related to maximum life span in the heart and brain of mammals. FASEB J 2000, 14(2):312-318.

50. Sipos I, Tretter L, Adam-Vizi V: Quantitative relationship between inhibition of respiratory complexes and formation of reactive oxygen species in isolated nerve terminals. J Neurochem 2003, 84(1):112-118.

51. Zhang QG, Laird MD, Han D, Nguyen K, Scott E, Dong Y, Dhandapani KM, Brann DW: Critical role of NADPH oxidase in neuronal oxidative damage and microglia activation following traumatic brain injury. PLoS One 2012, 7(4):e34504. 
52. Surace MJ, Block ML: Targeting microglia-mediated neurotoxicity: the potential of NOX2 inhibitors. Cell Mol Life Sci 2012, 69(14):2409-2427.

53. Qin L, Liu Y, Wang T, Wei SJ, Block ML, Wilson B, Liu B, Hong JS: NADPH oxidase mediates lipopolysaccharide-induced neurotoxicity and proinflammatory gene expression in activated microglia. $J$ Biol Chem 2004, 279(2):1415-1421.

54. Wang T, Qin L, Liu B, Liu Y, Wilson B, Eling TE, Langenbach R, Taniura S, Hong JS: Role of reactive oxygen species in LPS-induced production of prostaglandin E2 in microglia. J Neurochem 2004, 88(4):939-947.

55. Rodriguez-Pallares J, Parga JA, Munoz A, Rey P, Guerra MJ, Labandeira-Garcia الـ Mechanism of 6-hydroxydopamine neurotoxicity: the role of NADPH oxidase and microglial activation in 6-hydroxydopamine-induced degeneration of dopaminergic neurons. J Neurochem 2007, 103(1):145-156.

56. Choi SH, Aid S, Kim HW, Jackson SH, Bosetti F: Inhibition of NADPH oxidase promotes alternative and anti-inflammatory microglial activation during neuroinflammation. J Neurochem 2012, 120(2):292-301.

57. Wang Q, Tompkins KD, Simonyi A, Korthuis RJ, Sun AY, Sun GY: Apocynin protects against global cerebral ischemia-reperfusioninduced oxidative stress and injury in the gerbil hippocampus. Brain Res 2006, 1090(1):182-189.

58. Jensen MD, Sheng $W$, Simonyi A, Johnson GS, Sun AY, Sun GY: Involvement of oxidative pathways in cytokine-induced secretory phospholipase A2-IIA in astrocytes. Neurochem Int 2009, 55(6):362-368.

59. Hsieh HL, Lin CC, Shih RH, Hsiao LD, Yang CM: NADPH oxidase-mediated redox signal contributes to lipoteichoic acid-induced MMP-9 upregulation in brain astrocytes. J Neuroinflammation 2012, 9:110.

60. Lekstrom-Himes JA, Kuhns DB, Alvord WG, Gallin J: Inhibition of human neutrophil IL-8 production by hydrogen peroxide and dysregulation in chronic granulomatous disease. J Immunol 2005, 174(1):411-417.

61. Brown KL, Bylund J, MacDonald KL, Song-Zhao GX, Elliott MR, Falsafi R, Hancock RE, Speert DP: ROS-deficient monocytes have aberrant gene expression that correlates with inflammatory disorders of chronic granulomatous disease. Clin Immunol 2008, 129(1):90-102.

62. Segal BH, Davidson BA, Hutson AD, Russo TA, Holm BA, Mullan B, Habitzruther M, Holland SM, Knight PR 3rd: Acid aspiration-induced lung inflammation and injury are exacerbated in NADPH oxidase-deficient mice. Am J Physiol Lung Cell Mol Physiol 2007, 292(3):L760-L768.

63. Schappi M, Deffert C, Fiette L, Gavazzi G, Herrmann F, Belli D, Krause KH: Branched fungal beta-glucan causes hyperinflammation and necrosis in phagocyte NADPH oxidase-deficient mice. J Pathol 2008, 214(4):434-444.

64. Han W, Li H, Cai J, Gleaves LA, Polosukhin W, Segal BH, Yull FE, Blackwell TS: NADPH oxidase limits lipopolysaccharide-induced lung inflammation and injury in mice through reduction-oxidation regulation of NF-kappaB activity. J Immunol 2013, 190(9):4786-4794.

65. Barichello T, Machado RA, Constantino L, Valvassori SS, Reus GZ, Martins MR, Petronilho F, Ritter C, Quevedo J, Dal-Pizzol F: Antioxidant treatment prevented late memory impairment in an animal model of sepsis. Crit Care Med 2007, 35(9):2186-2190.

doi:10.1186/1742-2094-11-36

Cite this article as: Hernandes et al:: The role of Nox2-derived ROS in the development of cognitive impairment after sepsis. Journal of

Neuroinflammation 2014 11:36.

\section{Submit your next manuscript to BioMed Central and take full advantage of:}

- Convenient online submission

- Thorough peer review

- No space constraints or color figure charges

- Immediate publication on acceptance

- Inclusion in PubMed, CAS, Scopus and Google Scholar

- Research which is freely available for redistribution 